\title{
ANÁLISE INTERDISCIPLINAR DAS ESTÓRIAS DO LIVRO "ESPORTES DE AVENTURA" NUMA PERSPECTIVA STEAM
}

\author{
Dandara Lima Viana ${ }^{\mathbf{a}}$ \\ Cleusa Suzana Oliveira de Araujo ${ }^{\mathbf{b}}$ \\ Daniela dos Santos Cavalcante ${ }^{\mathbf{c}}$
}

A R T I C L E I N F O

\author{
Palavras chave: \\ Interdisciplinaridade; \\ Estória de aventura; \\ Ensino. \\ E-mail: \\ a dandra.lv@hotmail.com \\ bcsrarujo@uea.edu.br \\ cdanielacavalcante18@gmail.com
}

\section{R E S U M O}

Este artigo foi desenvolvido a partir da análise do livro "Esporte de Aventura", componente da coleção "Almanaque do sítio" que contém vários livros com diferentes temáticas. O livro é composto por estórias que se passam no cenário do famoso Sítio do Pica Pau Amarelo, uma composição do autor brasileiro Monteiro Lobato, que foi adaptada para televisão com uma série infanto-juvenil. Esta pesquisa se enquadra predominantemente como pesquisa qualitativa, no que concerne ao interesse pela ênfase na qualidade dos fenômenos educacionais, no que tange aos fenômenos humanos, à sua multiplicidade e a suas interconexões. A proposta desta análise é identificar como trabalhar conjuntamente diferentes disciplinas do $6^{\circ}$ ao $9^{\circ}$ ano do ensino fundamental, a partir das estórias do livro, em uma proposta interdisciplinar, mostrando articulação entre as diferentes disciplinas numa abordagem STEAM Ciência, Tecnologia, Engenharia, Artes e Matemática, bem como identificar os conteúdos que o professor pode desenvolver na sala juntamente com propostas de atividades para esse conteúdo. Através dos resultados obtidos com a pesquisa pode-se constatar que com apenas esse livro é possível fazer no mínimo 10 (dez) atividades interdisciplinares com os alunos, abordando as disciplinas de artes, matemática, ciências, educação física, história, geografia, física, língua portuguesa e inglês. Ainda é possível explorar muito mais do livro.

\section{INTRODUÇÃO}

O sistema educacional em boa parte do mundo trabalha com o ensino por áreas: Humanas, Exatas e Biológicas. Essas áreas se subdividem em disciplinas: Português, Matemática, História, Geografia, Filosofia, e assim por diante. As disciplinas ainda se subdividem em assuntos a serem abordados em sala. Esse sistema é chamdo por alguns autores de "fragmentação do ensino" (BRAGA et al., 1998, p. 33). Apesar de ser uma forma concretizada nas escolas de trabalho, existem muitas críticas a essa forma de transmitir o Revista REAMEC, Cuiabá - MT, V. 6, n. Especial, dez 2018, ISSN: 2318-6674 
conhecimento. Esse trabalho tem a intencionalidade de problematizar esse sistema fragmentada e trazer uma proposta de ensino interdisciplinar, em que todas as áreas do conhecimento aparecem vinculadas para o melhor entendimento dos assuntos abordados pelo professor dentro da sala de aula.

O objetivo principal dessa pesquisa é analisar o livro "esportes de aventuras" percebendo como as disciplinas escolares estão sendo abordadas no livro. Os objetivos específicos são: identificar as disciplinas que podem ser trabalhadas com apoio das estórias do livro; propor atividades para os professores dessas determinadas disciplinas; e apresentar as propostas para os professores trabalharem em sala de aula com seus alunos.

A proposta deste artigo é apresentar a análise do livro "Esporte de Aventura" numa perspectiva interdisciplinar na abordagem STEAM, sigla em inglês de Ciência, Tecnologia, Engenharia, Artes e Matemática, ao identificar como diferentes disciplinas do $6^{\circ}$ ao $9^{\circ}$ ano do ensino fundamental podem ser trabalhadas conjuntamente. Ao analisar as estórias foi possível mostrar como as diferentes disciplinas estão presentes, neste aspecto, foi elaborado uma proposta dos conteúdos que o professor pode desenvolver na sala de aula.

Essa tendência educacional já vem ganhando espaço no Brasil, muito embora de forma insipiente. No entanto, os educadores acreditam no rápido avanço da interligação dessas disciplinas em um currículo de aprendizagem interdisciplinar. A integração do currículo de engenharia e tecnologia com as disciplinas de ciência e matemática, por exemplo, tem potencial de transformar a aula em algo mais significativo e interessante, além de desenvolver o pensamento crítico e a habilidade de resolver problemas complexos (DUARTE et al., 2015).

A abordagem do STEAM se mostrou favorável, pois permite uma articulação interdisciplinar e científica, entendendo que os conteúdos científicos com valor cultural, quando contextualizados, passam a ter significado para os alunos (SANTOS, 2008). Ou seja, proporciona aos alunos o aprendizado dos conceitos científicos que condicionam o exercer de sua cidadania numa sociedade tecnológica, por meio da interdisciplinaridade. Lorenzetti e Delizoicov (2001) afirmam que "aumentar o nível de entendimento público da Ciência é hoje uma necessidade, não só como um prazer intelectual, mas também como uma necessidade de sobrevivência do homem". Tendo em vista que é caracterizada como uma necessidade 
cultural e amplia o universo de conhecimentos científicos, pois hoje a sociedade convive mais intensamente com a diversidade de conceitos difundidos por meio dos recursos tecnológicos.

Nessa perspectiva, o conhecimento é o eixo principal que implica em melhoria da qualidade de vida da população e gera o desenvolvimento sustentável, na medida em que promove a conscientização dos direitos do cidadão, desenvolve competências e habilidades, para que possam ser úteis ao cidadão no campo profissional (ROITMAN, 2005). É indiscutível a importância de uma educação científica que crie nas escolas um ambiente e clima propícios para a aprendizagem e promova o trabalho conjunto e integrado de conceitos e valores no campo da Ciência.

\section{METODOLOGIA}

Esta pesquisa se enquadra predominantemente como pesquisa qualitativa, no que concerne ao interesse pela ênfase na qualidade dos fenômenos educacionais, no que tange aos fenômenos humanos, à sua multiplicidade e a suas interconexões. Há necessidade, neste contexto, de uma investigação bibliográfica, desenvolvido a partir de uma análise do livro "Esporte de Aventura”, componente da coleção "Almanaque do sítio" que contém vários livros com diferentes temáticas (GASQUES, 2005).

O livro foi escolhido por conter estórias em um ambiente conhecido desde as crianças até os adultos, podendo alcançar vários públicos e instigar interesse pela leitura, além de serem estórias curtas podendo ser lido esporadicamente. Além de falar sobre esportes, que é uma temática que atrai o público infanto-juvenil por fazer parte do seu cotidiano.

Tendo observado esses aspectos foi realizada a leitura do livro, disponível na biblioteca de uma Escola Pública Estadual que atende o Ensino Fundamental II e Médio, de Manaus, Amazonas. No decorrer da leitura foi sendo identificadas as disciplinas, que poderiam ser trabalhadas com aquela estória e pensado em propostas de atividades para os professores trabalharem com os alunos na sala, para tanto o suporte teórico foi a análise de conteúdo de Bandin (2011). A proposta é que essas atividades sejam realizadas conjuntamente, não apenas um professor, mas todos os professores que tiverem suas matérias contempladas com determinada estória possam conhecer a história real que está associada aos 


\section{REVISTA REAMEC}

Revista ta Rete Amazônica de Eduração

em Ciências e Matemática
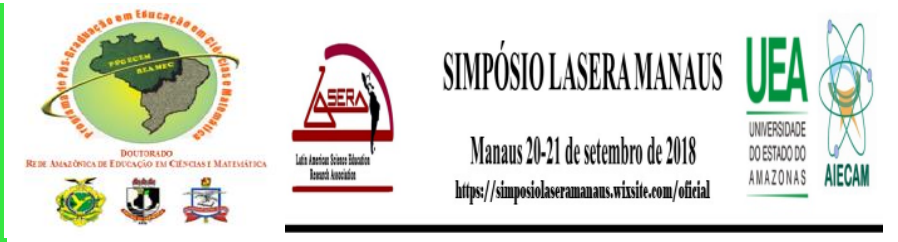

aspectos culturais e científico do contexto estudado, associar com os conteúdos curriculares e científicos promovendo uma abordagem mais completa e contextualizada. Por isso foi construído um quadro com os títulos das estórias, a página em que ele está, um resumo do que se trata e a atividade proposta, para que no momento do planejamento dos professores eles possam utilizar o quadro para elaborar seus planos de aula.

Como o nome diz essas atividades são propostas, sabendo que os professores atuantes na sala de aula têm total capacidade de elaborar atividades criativas e dinâmicas com seus alunos, essas propostas são nortear o trabalho do professor.

\section{RESULTADOS E DISCUSSÃO}

\subsection{A proposta interdisciplinar e a abordagem STEAM}

A proposta de um trabalho interdisciplinar não é recente, porém cada vez mais essa discussão torna-se pertinente. As disciplinas estão ficando mais fragmentadas como se não houvesse uma conexão entre elas, os alunos não conseguem compreender que a estória caminho lado a lado com a matemática, que a educação física complementa a geografia, que a artes tem ligação com a língua portuguesa, e todas essas juntas trazem as informações necessárias para o desenvolvimento do aluno na sua totalidade.

É necessário que após uma experiência escolar o aluno perceba que o mundo tem complexidades que podem ser compreendidas através do olhar das multidisciplinar. Não é possível olhar os fatos apenas pelo olhar exato da matemática ou da física, ou apenas pelas teorias filosóficas e sociólogas, mas para se entender as coisas que estão ao redor e para ter um entendimento completo da realidade todas as disciplinas são importantes. "A extrema compartimentalização do conhecimento em disciplinas isoladas produz nos estudantes a falsa impressão de que o conhecimento e o próprio mundo são fragmentados. Tal visão implica numa formação que acaba sendo, na realidade, uma deformação" (BRAGA et al., 1998, p. 33). Ao fragmentar os conteúdos formam-se especialistas incapazes de analisar o todo e competentes para analisar as partes. Não vivemos em um mundo fragmentado, mas em um 
complexo de diferentes realidades e teorias, e é necessário que na escola o aluno comece a entender esse multiuniveso dentro de um único universo.

Quando paramos para analisar o mundo a nossa volta começamos a perceber que a conexão entre os mais variados assuntos faz mais sentido do que a fragmentação. "Ciência, arte, tecnologia e filosofia, ou seja, raciocínio lógico, criatividade, desenvolvimento de técnicas e capacidade de reflexão e abstração fazem mais sentido conectados e são cada vez mais necessários diante de um mundo cada vez mais complexo" (SILVEIRA, 2018, p. 24). Como diz Silveira (2018) tudo faz mais sentido conectado. A interdisciplinaridade precisa está cada vez mais presente nas escolas, desde a educação infantil até o ensino superior, pois assim teremos menos especialistas e mais pensadores.

É comum que alunos que gostem de exatas, não gostem de estória e alunos que gostem de filosofia não consigam aprender física. Mas essas coisas acontecem porque a escola desde a educação infantil apresenta para as crianças um mundo fragmentado e quanto mais vai se evoluindo nas séries, mas fragmentado fica esse processo. A finalidade do ensino interdisciplinar é que os assuntos se complementem e que os alunos entendem que todo conhecimento é necessário e útil para nossa vida em sociedade.

É importante que os alunos percebam que todo conhecimento é uma atividade humana que não se encerra apenas numa metodologia. Como todos os empreendimentos do Homem, está relacionado com todas as formas deste interagir com o mundo à sua volta. $\mathrm{E}$ que os problemas e respostas encontrados e dados ao longo da história não se constituem em verdades absolutas, pois estão diretamente ligados ao contexto sócio-cultural do momento e ao espaço analisados (BRAGA et al., 1998,p. 38).

Todo o conhecimento é necessário e pertinente para nosso cotidiano. Na sala de aula o aluno precisa ser instigado de diversas formas a buscar e se aprofundar nos assuntos propostos, o professor é o mediador desse conhecimento, e por isso tem que estar sempre atento para buscar novas formas de instigar esse aluno. E quanto mais esse aluno se aprofunda nos conhecimentos, mas sua mente vai se abrir para novas experiências e perceber que dividir os conhecimentos em disciplinas foi apenas uma foram de organizar as ideias para ensinar, mas que o mundo não está fragmentado dessa forma, ele é um todo que precisar ser entendido dessa maneira. Dessa forma ele vai entender que o conhecimento é uma atividade humana, quer dizer que a busca por conhecimento, seja ele qual for, é uma forma de compreendermos o mundo que nos cerca. 
Como dito anteriormente a proposta interdisciplinar não é recente, a muito tempo estudiosos são apontavam a necessidade de se trabalhar as matérias interligadas nas escolas. Na década de 1990 surgiu o movimento STEM que após acrescentar Artes a sua sigla ficou STEAM, que surgiu para identificar propostas que englobassem as principais disciplinas, com o objetivo de promover uma educação sem barreiras disciplinares.

O movimento STEM (acrônimo em inglês para science, technology, engineeringandmathematic) surgiu nos Estados Unidos na década de 1990 para identificar qualquer ação ou prática educacional envolvendo as disciplinas de ciência, tecnologia, engenharia e/ou matemática. Depois de alguns anos, pesquisadores passam a advogar que a arte deveria ser integrada às demais áreas, dando origem ao movimento STEM to STEAM. O principal argumento da educação STEAM é promover uma educação sem barreiras entre as disciplinas, que promova a criatividade e a inovação. A rede de educadores que abordam essa prática tem gradativamente se espalhado pelo mundo (SILVEIRA, 2018, p. 24-25).

O STEAM é um dos mais recentes movimentos preocupados com a integração das disciplinas. Percebendo a importância de uma educação conjunta, com todas as disciplinas trabalhando juntas tem respaldo o trabalho com o livro "Esportes de Aventura" dentro de sala e abre o caminho para a análise da coleção completa, para contribuir com um ensino interdisciplinar nas escolas. As escolas precisam desses apoios didáticos para auxiliar no trabalho interdisciplinar.

\subsection{Análise do livro "Esportes de Aventura” uma proposta interdisciplinar}

O quadro 1 apresenta os resultados obtidos na análise do livro "Esportes de Aventuras". Na primeira coluna estão identificadas as páginas da estória em destaque, na segunda o título, na terceira um breve resumo sobre os fatos trazidos no decorrer da narrativa e os personagens que a compõem, por fim a quarta coluna traz as disciplinas em que podem ser abordadas a referente estória, os conteúdos que foram identificados a partir da leitura e proposta de atividades que podem ser aplicadas pelos professores na sala.

Através da análise desse livro e da construção desse material para suporte aos professores busca-se que se apresente na escola uma proposta interdisciplinar, em um de seus aspectos que é o de trabalhar diferentes disciplinas a partir de um tema gerador. Contudo ela pode ser caracterizada em dois aspectos, que são: 
A proposta interdisciplinar de ensino pode ser concretizada basicamente sobre dois aspectos. A partir de uma abordagem que privilegie a compreensão do processo de produção do conhecimento, ou, o que é mais comum, a partir de um tema gerador único que irá ser trabalhado pelas diferentes disciplinas (BRAGA, et al., 1998,p. 33).

QUADRO 1: Propostas de assuntos a serem abordados por disciplinas em cada título da obra "Esportes de Aventura".

\begin{tabular}{|c|c|c|c|}
\hline Páginas & Título & Resumo & Propostas de atividade \\
\hline 22 à 24 & Esportista radical & $\begin{array}{l}\text { Ensina como fazer um boneco } \\
\text { reciclável usando tubo de cola, } \\
\text { canudos e palitos de churrasco. } \\
\text { Mostra os materiais que precisa } \\
\text { para montar e o passo a passo da } \\
\text { construção. }\end{array}$ & $\begin{array}{c}\text { Artes - Atividade Manual } \\
\text { Ciências - reciclagem } \\
\text { Língua Portuguesa - Construir } \\
\text { uma estória usando o boneco como } \\
\text { personagem. }\end{array}$ \\
\hline 26-27 & $\begin{array}{l}\text { Corpo saudável, } \\
\text { mente feliz }\end{array}$ & $\begin{array}{l}\text { Quindim, Narizinho e Pedrinho } \\
\text { saem para uma caminhada pelo } \\
\text { sítio. Mas Quindim logo fica } \\
\text { cansado e Narizinho começa a dar } \\
\text { uma lição nele mostrando que } \\
\text { muitas pessoas estão buscando } \\
\text { fazer mais exercícios para manter a } \\
\text { saúde e aproveitar a natureza. }\end{array}$ & $\begin{array}{c}\text { Educação física: } \\
\text { - } \quad \text { reflexões sobre a } \\
\text { importância de praticar } \\
\text { exercícios. } \\
\text { - } \quad \text { Esportes praticados ao ar } \\
\text { livre } \\
\text { Benefícios de uma } \\
\text { caminhada para saúde. } \\
\text { Ciências: Por que o corpo humano } \\
\text { precisa de exercícios? }\end{array}$ \\
\hline $28-31$ & $\begin{array}{c}\text { Andar é simples e } \\
\text { gostoso }\end{array}$ & $\begin{array}{l}\text { Emília pergunta qual é o esporte } \\
\text { mais simples que existe. Chega-se } \\
\text { a conclusão de que é a caminhada } \\
\text { e Dona Benta explica como é esse } \\
\text { esporte e em quais lugares se } \\
\text { pratica. }\end{array}$ & $\begin{array}{c}\text { Geografia: Pesquisar sobre bons } \\
\text { lugares para caminhar em nossa } \\
\text { cidade } \\
\text { Educação Física: Fazer uma } \\
\text { caminhada com os alunos após } \\
\text { uma reflexão sobre a importância } \\
\text { da prática desse esporte. }\end{array}$ \\
\hline $32-33$ & A corrida da & Trata de um esporte de corrida & Geografia: Uso da bússola e \\
\hline
\end{tabular}

Revista REAMEC, Cuiabá - MT, V. 6, n. Especial, dez 2018, ISSN: 2318-6674

Revista do Programa de Doutorado da Rede Amazônica de Educação em Ciências e Matemática

http://periodicoscientificos.ufmt.br/ojs/index.php/reamec 
Revista ta Rede Amazôniza de Eduração em Ciências e Matemática
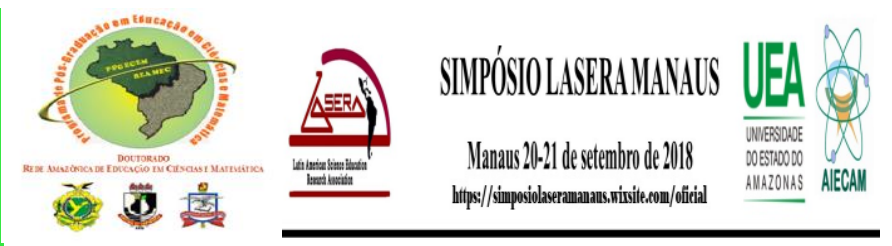

\begin{tabular}{|c|c|c|c|}
\hline & bússola. & $\begin{array}{l}\text { denominado “Orientação" em que } \\
\text { podem participar em times ou } \\
\text { individualmente. Os competidores } \\
\text { recebem um mapa com o percurso } \\
\text { e os trechos que terão de passar } \\
\text { para chegar ao local determinado. } \\
\text { Para cumprir da melhor maneira o } \\
\text { percurso terão que usar bússola e } \\
\text { cronômetro. }\end{array}$ & $\begin{array}{l}\text { leitura de mapa (cartografia) } \\
\text { Matemática: Uso do cronômetro e } \\
\text { cálculo de tempo. } \\
\text { Física: Como é o funcionamento } \\
\text { da bússola. } \\
\text { Interdisciplinar (Educação física, } \\
\text { Geografia, Matemática e física) } \\
\text { Realizar uma prova de } \\
\text { “Orientação” com a turma nos } \\
\text { arredores da escola. }\end{array}$ \\
\hline 34-35 & $\begin{array}{l}\text { Corrida de } \\
\text { Aventura }\end{array}$ & $\begin{array}{l}\text { Corrida de aventura é uma } \\
\text { competição que envolve vários } \\
\text { esportes, dependendo do lugar em } \\
\text { que ocorre a competição. }\end{array}$ & $\begin{array}{c}\text { Educação Física: História da } \\
\text { corrida de aventura e esportes já } \\
\text { inclusos na corrida no Brasil e em } \\
\text { outros países. } \\
\text { Ciências: Resistência do corpo } \\
\text { humano. }\end{array}$ \\
\hline 36-39 & $\begin{array}{c}\text { Cavalgada em } \\
\text { turma }\end{array}$ & $\begin{array}{l}\text { Esporte adaptado da prática dos } \\
\text { tropeiros, homens que levaram } \\
\text { mercadorias nos lombos dos } \\
\text { cavalos, em tropas para lugares } \\
\text { distantes. }\end{array}$ & $\begin{array}{c}\text { História } \\
\text { - } \quad \text { Quem eram os tropeiros? } \\
\text { - } \quad \text { Época em que eles } \\
\text { surgiram. (Brasil Colônia) } \\
\text { Educação Física: História do } \\
\text { esporte Cavalgada }\end{array}$ \\
\hline $40-41$ & $\begin{array}{c}\text { Deslizando na } \\
\text { neve }\end{array}$ & $\begin{array}{c}\text { Explora o snowboard e sua } \\
\text { história. }\end{array}$ & $\begin{array}{l}\text { Geografia: } \\
\text { Países em que o snowboard pode } \\
\text { ser praticado. } \\
\text { • } \quad \text { Temperatura } \\
\text { • } \quad \text { Localização no globo } \\
\text { Porque em outros países é } \\
\text { frio e em outros não? } \\
\text { Educação Física: Como se pratica }\end{array}$ \\
\hline
\end{tabular}

Revista REAMEC, Cuiabá - MT, V. 6, n. Especial, dez 2018, ISSN: 2318-6674

Revista do Programa de Doutorado da Rede Amazônica de Educação em Ciências e Matemática http://periodicoscientificos.ufmt.br/ojs/index.php/reamec 


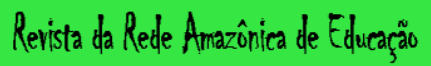
em Ciềncias e Maternatica

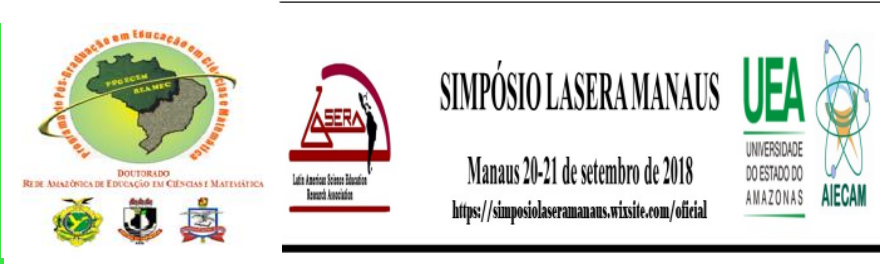

\begin{tabular}{|c|c|c|c|}
\hline & & & o snowboard. \\
\hline $42-43$ & Surfe na areia & $\begin{array}{l}\text { A invenção de um novo esporte } \\
\text { "sandboard" nas praias brasileiras, } \\
\text { que é deslizar nas areias com } \\
\text { pranchas. }\end{array}$ & $\begin{array}{c}\text { Educação Física: Associação do } \\
\text { sandboard e o snwboard. } \\
\text { Geografia: } \\
\text { - Locais no Brasil que tem } \\
\text { dunas para se praticar o } \\
\text { sandboard } \\
\text { - O que são dunas? } \\
\text { Inglês: Apropriação de palavras } \\
\text { em inglês na nossa língua. }\end{array}$ \\
\hline 44-47 & $\begin{array}{l}\text { No topo do } \\
\text { mundo }\end{array}$ & $\begin{array}{l}\text { Dona Benta conta a história do } \\
\text { surgimento do alpinismo e como } \\
\text { ele é praticado. }\end{array}$ & $\begin{array}{c}\text { Educação Física: História do } \\
\text { Alpinismo } \\
\text { Geografia: } \\
\text { - } \quad \text { Formação das rochas e } \\
\text { montanhas } \\
\text { - Montanhas Brasileiras } \\
\text { - Maiores montanhas do } \\
\text { mundo } \\
\text { Matemática / Engenharia : } \\
\text { Escala } \\
\text { Construção de uma } \\
\text { montanha em escala. }\end{array}$ \\
\hline
\end{tabular}

\subsection{Correlacionando e discutindo os resultados da análise}

O objetivo é que esse material possa auxiliar os professores na elaboração de atividades interdisciplinares e que possa contribuir para uma educação sem barreiras de disciplinas. Entendo que todos as disciplinas trabalham em conjunto e que os alunos precisam dessa ligação entre as disciplinas para fortalecer o conhecimento. Mesmo que para alguns 
autores a escola não está preparada para promover um ambiente estimulante de educação científica e tecnológica (TEIXEIRA, 2003). Muito dessa problemática, deve-se ao fato dos docentes não levarem em conta o conhecimento que os educandos já possuem e por conceberem a aquisição do novo conhecimento como uma adição, que pode ser atingida através de meras repetições, reprodução de conceitos científicos, destituídos de significado, de sentido e de aplicabilidade (LORENZETTI e DELIZOICOV, 2001).

Se essa proposta for colocada em prática na sala de aula os alunos poderiam ver como os assuntos conversam entre si, cada estória trabalha mais de uma matéria que pode não haver ligação entre si aparentemente, mas que com o auxílio da história real se complementam. É possível que os professores trabalhem p mesmo assunto, mas cada um no seu tempo de aula com seu planejamento, contudo seria interessante que eles realizassem uma atividade comum em que os alunos pudessem juntar todos os ensinamentos na mesma atividade.

Através dos resultados obtidos com a pesquisa pode-se constatar que com apenas esse livro é possível fazer no mínimo 10 (dez) atividades interdisciplinares no ano com os alunos, abordando as disciplinas de artes, matemática, ciências, educação física, história, geografia, física, língua portuguesa e inglês. Sendo, que ainda é possível explorar mais, tanto este livro, como os demais da coleção. Nesta perspectiva pode-se perceber a viabilidade em problematizar questões do cotidiano e articular com a interdisciplinaridade, pois a abordagem STEAM tem como propósito o compartilhamento de conhecimento, mudança da postura perante desafios, promoção da habilidade de identificar perguntas e problemas da vida real, criando assim, um ambiente onde é possível chegar a conclusões baseadas em fatos e evidências. Tudo isso relacionando e interligando as disciplinas de ciências, tecnologia, engenharia, artes e matemática, de forma a adquirir conhecimento construtivo, consciente e reflexivo (GENELLO, et al., 2015).

Mas para que tudo isso tone-se realidade é necessário primeiramente que os professores entendam a importância do ensino interdisciplinar e esteja disposta a realizá-lo, pois, exige muito trabalho de pesquisa por parte do professor e uma disponibilidade de trabalhar com o outro, debater ideias, montar estratégias, discordar, pesquisar, analisar, para que possam chegar a uma comum ideia e colocá-la em prática. Para Cardoso Brabo e Sousa 


\section{REVISTA REAMEC}

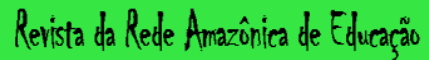

em Ciênciass e Matemática
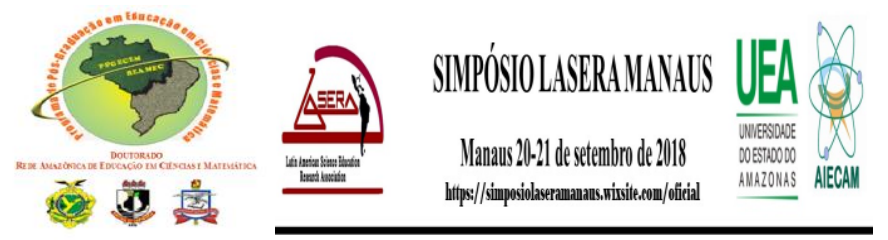

(2006), grande parte dos professores, de todos os níveis de ensino, possui uma visão equivocada sobre Ciência, do ponto de vista da epistemologia contemporânea. Essas visões deformadas sobre Ciência constituíam-se em um dos principais obstáculos para a renovação do ensino, uma vez que influenciavam fortemente a forma de pensar, nas atitudes e na maneira de ensinar dos professores.

É uma dedicação a mais por parte do professor, bem como por parte do aluno que está acostumado a estudar para cada matéria e aprender aquele conteúdo básico, sem precisar fazer uma ligação com outra matéria. STEAM é uma proposta de estudar as disciplinas juntas, analisando todas as partes do assunto o processo fica mais complexo e cheio de obstáculos. O aluno pode até achar tudo muito chato no começo pela exigência intelectual. Porém quando começam a aparecer os resultados, resolver problemas do cotidiano, e ele enxergar que tudo está interligado, o assunto faz sentindo e ganha vida, tornado o ensino-aprendizagem mais eficiente.

Em um assunto que ele iria apenas aprender um novo esporte, ele passa a estudar geograficamente onde esse esporte é praticado e porque é pratica apenas em determinados lugares, qual é a história desse esporte, aprende como usar um novo instrumento como a bússola que é usado naquele esponte, na aula de artes ele desenha essa bússola, e assim por diante. Aquilo que era apenas um conteúdo ganha forma e começa a fazer sentido para o aluno e o instiga para aprender mais.

\section{CONCLUSÃO}

A interdisciplinaridade é um diferencial na aprendizagem dos alunos. Nesse trabalho podemos explorar os muitos benefícios que essa posposta de ensino tem para o ensinoaprendizagem dos alunos e dos professores nas escolas. Depois dessa leitura não é difícil perceber que o ensino interdisciplinar é uma ótima opção para estimular os alunos a aprenderam mais e por si mesmos e irem mais fundos nas pesquisas. Até mesmo para os professores que passam a explorar conhecimentos além do que suas matérias exigem, toando profissionais mais completos e capazes de explorar novos horizontes do conhecimento. 


\section{REVISTA REAMEC}

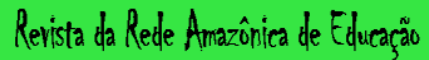

em Ciêneias e Matemática
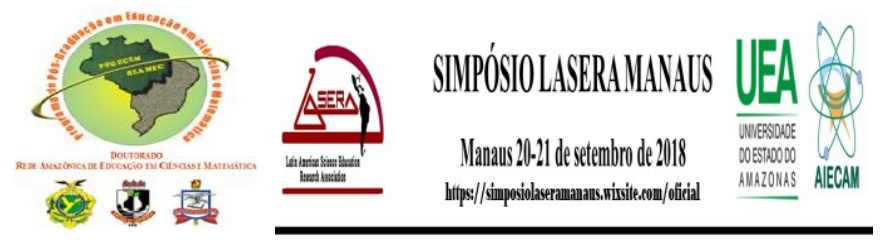

Nessa proposta de trabalho com o livro "Esportes de Aventura", verificamos a possibilidade em articular as bases conceituis curriculares de várias disciplinas, o que permite uma excelente indicação para que esta interdisciplinaridade possa ser trabalhada dentro da proposta STEAM, permitindo que o aluno exploro mais sua realidade, busque a solução de problemas e tenha uma visão menos pragmática ou linealizada do ensino.

Essa é a ideia do ensino interdisciplinar, não olhar uma peça de arte e limitá-la a matéria de artes, mas conseguir ultrapassar essa barreira do olhar fragmentado e enxergar o que tem por trás dessa peça, qual é sua história, qual seu diâmetro, com qual material foi feito, onde pode se encontrar essa material, é possível reproduzi-lo com outro material. Essas questões vão norteando atividades diferenciadas que podem ser realizadas na sala de aula.

Esperamos que essa pesquisa possa auxiliar no trabalho de muitos colegas professores e seja uma porta para outras pesquisas vindouras.

\section{REFERENCIAS}

BARDIN, L. Análise de Conteúdo. $3^{\text {a }}$ reimp. Edição revista e ampliada, São Paulo: Edições 70, 2011.

BRAGA, M.A.B.; FREITAS, L.D. GUERRA,Andreia. REIS, José Claudio. Interdisciplinaridade no ensino das ciências a partir de uma perspectiva histórico-filosófica. Caderno Brasileiro de Ensino de Física, ISSN-e 2175-7941, Vol. 15, №. 1, 1998, págs. 3246.

CARDOSO BRABO, J.; SOUSA, C.M. Pedagogia e pedagogos no imaginário dos professores de ciências brasileiros: um estudo preliminar. Revista Electrónica de Enseñanza de las Ciência. 2006. 5(3):430.

DUARTE, A.J., MALHEIRO, B.; RIBEIRO, C.; SILVA, M.F.; FERREIRA, P. e GUEDES, P. Developing an aquaponics system to learn sustainability and socialcompromise skills. Journal of Technology and Science Education. Vol 5(4): 235-254, 2015.

GENELLO, L.; FRY, J.P.; FREDERICK, J. A.; LI, X.; LOVE, D.C. Fish in the Classroom: A Survey of the Use of Aquaponics in Education. European Journal of Health \& Biology Education, 4(2), 9-20, 2015.

GASQUES, M.V. Esportes de aventura. Ilustrações Traviatta Produções Artísticas, São Paulo. Globo, 2005. (Coleção Almanaque Sítio). 


\section{REVISTA REAMEC}

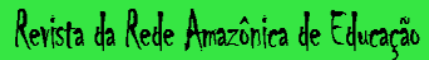

em Ciências e Matemática
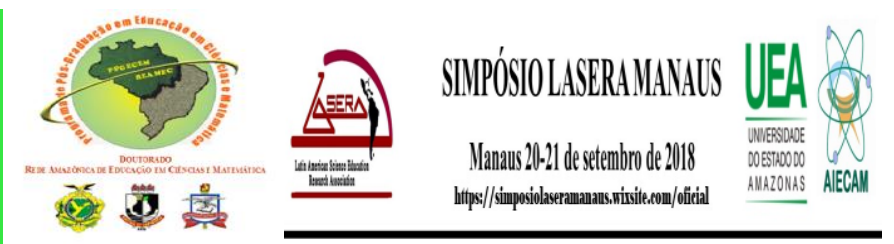

LORENZETTI, L.; DELIZOICOV, D. Alfabetização científica no contexto das séries iniciais. Ensaio - Pesquisa em Educação em Ciências. 3(1)1-17, Jun. 2001.

SANTOS, W.L.P. Educação Científica Humanística em Uma Perspectiva Freireana: Resgatando a Função do Ensino de CTS. Alexandria Revista de Educação em Ciência e Tecnologia, v.1, n.1, p. 109-131. ISSN 1982-5153. 2008.

ROITMAN, I. Ciência para os jovens: falar menos e fazer mais. In: Werthein , J; Cunha, C. (Orgs.). Educação científica e desenvolvimento: o que pensam os cientistas. Brasília: UNESCO, Instituto Sangari, 232 p. 2005.

SILVEIRA, J.R.A. Arte e Ciência: uma reconexão entre as áreas. Cienc. Cult. vol.70 no.2 São Paulo Apr./June 2018 (p. 24-25). Disponível em: http://dx.doi.org/10.21800/231766602018000200009

TEIXEIRA, P. M. M. A Educação Científica sob a perspectiva da Pedagogia Histórico-Crítica e do movimento CTS no ensino de Ciências. Ciência \& Educação, Bauru, v. 9, n. 2, p. 177 190, 2003. 